\title{
Elaboração de biscoitos de chocolate com substituição parcial da farinha de trigo por polvilho azedo e farinha de albedo de laranja
}

\author{
Chocolate biscuits preparation with partial substitution of wheat flour by \\ fermented cassava starch and orange albedo flour
}

\begin{abstract}
Aline Alves Oliveira Santos ${ }^{\mathrm{I}^{*}}$ Izabel Veras Cristina e Silva $^{\mathrm{I}}$ João Paulo Almeida dos Santos ${ }^{\mathrm{II}}$ Danielle Gomes Santana ${ }^{\text {II }}$ Meirielly Lima Almeida ${ }^{\text {II }}$ Paulo Sergio Marcellini ${ }^{\text {II }}$
\end{abstract}

\section{RESUMO}

Os consumidores estão cada vez mais exigentes $e$ preocupados com a saúde e, por consequência, exigindo produtos naturais que deverão ser seguros e promover qualidade de vida. O presente trabalho teve o objetivo de desenvolver biscoitos com farinhas mistas de polvilho azedo $e$ farinha de albedo de laranja, utilizando um planejamento fatorial $2^{3}$, com variáveis independentes: concentração de polvilho azedo, açúcar e farinha de albedo de laranja, e variáveis respostas: as características sensoriais: aparência, aroma, textura e sabor, além da impressão global, utilizando escala hedônica estruturada de nove pontos. Os biscoitos foram avaliados também quanto às características físico-químicas. As médias obtidas para as características sensoriais estiveram na faixa que vai de cinco (não gostei nem desgostei) até sete (gostei moderadamente), não apresentando diferença significativa $(P \leq 0,05)$ para todas as características sensoriais avaliadas. Dessa maneira, foi possível escolher a formulação ideal obtida de acordo com os parâmetros nutricionais, por não existir diferença sensorial significativa, que foi $35 \%$ de polvilho azedo, $100 \%$ de açúcar e 7,5\% de farinha de albedo de laranja. No teste sensorial comparativo com os biscoitos comercial, padrão e otimizado, as características sensoriais aparência, sabor e textura apresentaram diferença significativa $(P \leq 0,05)$. As características físico-químicas apresentaram resultados correspondentes aos padrões estabelecidos pela legislação brasileira, e o teor de fibra bruta do biscoito otimizado foi de 3,08\%, assim, pode ser classificado como biscoito "fonte de fibras".

Palavras-chave: polvilho azedo, albedo de laranja, biscoito, ABSTRACT análise sensorial.

The consumers are increasingly demanding and worried about health and, consequently, requiring natural products that should be safe and that promote life quality. The present research had the objective to develop biscuits with mixed flour of fermented cassava starch and orange albedo flour, using a $2^{3}$ factorial experimental. The independent variables were: concentration of fermented cassava starch, sugar and orange albedo flour, and the responses variables were the sensory characteristic: appearance, aroma, texture and flavor, in addition to overall impression, using a nine point hedonic structure scale. The biscuits were also evaluated for physicchemical properties. The average for sensory characteristic were in the range of five (not liked nor disliked) up to seven (like moderately), and it didn't show significant difference $(P \leq 0.05)$ for all sensory characteristics assessed. Thus, it was possible to choose the optimal formulation obtained according with the nutritional parameters, because there isn't sensory difference significant, which was: $35 \%$ of fermented cassava starch, $100 \%$ of sugar and $7.5 \%$ of orange albedo flour. In comparison with the commercial biscuits test, standard and optimized, sensory appearance, flavor and texture showed significant differences $(P \leq 0.05)$. The results correspond to standards set by Brazilian legislation, and crude fiber content of the biscuit was optimized at 3.08\%, thus, can be classified as biscuit "source of fiber".

Key words: fermented cassava starch, orange albedo flour, biscuit, sensory evaluation.

\section{INTRODUÇÃO}

A mandioca é uma cultura originária da América do Sul, pertencente à família da Euphorbiaceae, denominada botanicamente de Manihot esculenta Crantz. É amplamente conhecida

'Departamento de Tecnologia de Alimentos, Universidade Federal de Sergipe (UFS), 49100-000, São-Cristovão, SE, Brasil. Email: alinealveseng@hotmail.com. *Autor para correspondência.

"Departamento de Fisiologia, Faculdade de Farmácia, UFS, São-Cristovão, SE, Brasil. 
no Brasil por mandioca, macaxeira ou aipim (EMBRAPA, 2010). Dentre os principais produtos derivados da mandioca, destaca-se o polvilho azedo, um produto obtido a partir da fermentação da fécula de mandioca, utilizado como matéria-prima essencial para a confecção de biscoitos de polvilho, pão de queijo, sequilhos, entre outros (EL-DASHet al., 1994a), devido a sua capacidade de gerar massas, que quando assadas se expandem sem a necessidade de adição de fermento ou de processo de extrusão (DEMIATE \& CEREDA, 2000).

O polvilho azedo, segundo Resolução CNNPA nº12 de 1978, deve apresentar um teor máximo de $14 \%$ para umidade, $0,5 \%$ de resíduo mineral fixo, e o mínimo de $80 \%$ para amido, sendo a acidez o único parâmetro que o diferencia do polvilho doce, que deve ter um valor máximo de $5 \%$. Já a resolução n ${ }^{\circ} 263$, de setembro de 2005 , regulamenta um teor máximo de umidade de $18 \%$ para amido.

A indústria de sucos de laranja (Citrus sinensis) no Brasil gera um montante de resíduos de $42 \%$ do total da fruta (ÍTAVO et al., 2000), com destaque para o albedo de laranja (mesocarpo), que, segundo GONÇALVES et al. (2001), apresenta teor de 39,25\% de pectina, e, conforme SANTANA (2005), 76,50\% de fibras totais, apresentando relação de aproximadamente 3:1 para as fibras insolúveis/solúveis. Esse resíduo pode ser aplicado como matéria-prima no enriquecimento de alimentos.

A aplicação da tecnologia de farinhas mistas pode ser utilizada desde que a substituição parcial da farinha de trigo por outros tipos de farinhas não ocasione prejuízo à qualidade final dos produtos elaborados (EL-DASH et al., 1994b). Dentre esses produtos, o biscoito constitui uma boa alternativa, uma vez que são aceitos e consumidos por pessoas de qualquer idade, e sua longa vida de prateleira permite que sejam produzidos em grande quantidade e largamente distribuídos (GUTKOSKI et al., 2003).

A utilização de farinhas mistas a partir destas duas culturas nacionais pode agregar valor econômico e nutricional ao produto. Assim, este trabalho teve como objetivo desenvolver biscoitos com farinhas mistas de trigo, polvilho azedo e farinha de albedo de laranja, e avaliar suas características físico-químicas, sensoriais e a intenção de compras desses biscoitos.

\section{MATERIAL E MÉTODOS}

Material

Os ingredientes foram adquiridos no comércio local de Aracaju/SE: farinha de trigo, marca Dona Benta; polvilho azedo, marca Dinha Bá; achocolatado, marca Nescau; margarina, marca Pastela; fermento em pó químico, marca Dr. Oetker; açúcar refinado; sal e água mineral. O biscoito comercial utilizado para fins de comparação foi marca Afa, sabor chocolate.

Métodos

A farinha de albedo de laranja (parte branca esponjosa) foi obtida do bagaço da laranja variedade Pêra (Citrus sinensis), segundo metodologia proposta por SANTANA (2005). Inicialmente as laranjas foram lavadas, sanitizadas com solução de cloro ativo (marca Clorin) $198 \mathrm{mg} \mathrm{L}^{-1}$, por 10 minutos, e descascadas manualmente. Em seguida, a trituração úmida foi realizada em liquidificador (marca ARNO) com baixa velocidade por 15 segundos, numa proporção de 1:5 (albedo:água) em volume. A lavagem do material foi efetuada mediante a utilização de sacos de algodão, sob água corrente abundante, por um período de 30 minutos. A secagem foi realizada em estufa (40L), a $100^{\circ} \mathrm{C}$, durante cinco horas. Posteriormente, triturouse o albedo seco no liquidificador até a obtenção de uma farinha, sendo peneirada em tamis com malha de 500 mesh.

Para a caracterização da farinha de albedo de laranja e dos biscoitos, foram realizadas as análises de umidade, lipídios e cinzas, conforme metodologias descritas pelo INSTITUTO ADOLFO LUTZ (2005), e de proteínas, segundo metodologia proposta pela AOAC (2000), feitas em triplicata. O teor de fibra bruta foi analisado de acordo com metodologia do INSTITUTO ADOLFO LUTZ (2005), feita em duplicata. $\mathrm{O}$ teor de carboidratos foi determinado por diferença entre a massa seca total (100\%) e a soma das porcentagens dos teores de umidade, cinzas, proteínas, lipídios e fibra bruta. $\mathrm{O}$ valor calórico $\left(\mathrm{kcal} \cdot 100 \mathrm{~g}^{-1}\right)$ foi calculado pela soma dos resultados da multiplicação dos fatores gerais de conversão para lipídios e para carboidratos e proteínas, $9 \mathrm{kcal} \mathrm{g}^{-1}, 4 \mathrm{kcal} \mathrm{g}^{-1} \mathrm{e} 4 \mathrm{kcal} \mathrm{g}^{-1}$, respectivamente.

No processo de elaboração dos biscoitos, utilizou-se um planejamento experimental $2^{3}$, no qual as variáveis independentes foram os teores de polvilho azedo, açúcar e farinha de albedo de laranja, e, como variáveis dependentes, foram estudadas as características sensoriais (aparência, aroma, textura e sabor, e a impressão global). O planejamento fatorial $2^{3}$ apresentou seis pontos axiais e quatro repetições no ponto central, totalizando 18 ensaios (Tabela 1).

Para a produção de biscoitos tipo doce não fermentado, foi utilizada a metodologia descrita por FASOLIN et al. (2007), com a adição de apenas farinha de trigo e $7 \%$ de achocolatado. Este biscoito foi utilizado como padrão, para fins de comparação.

Para a análise sensorial, foi realizado inicialmente um estudo preliminar com 50 consumidores que avaliaram os biscoitos elaborados a partir do planejamento experimental. O teste afetivo, para comparação entre os biscoitos comercial, padrão e otimizado, foi realizado com 100 consumidores, não 
Tabela 1 - Valores médios da avaliação sensorial dos biscoitos com incorporação de diferentes teores de polvilho azedo, açúcar e farinha de albedo de laranja.

\begin{tabular}{|c|c|c|c|c|c|c|c|c|}
\hline \multirow[t]{2}{*}{ Ensaio } & \multicolumn{4}{|c|}{--------------------Variáveis codificadas"-------------------- } & \multicolumn{4}{|c|}{---------------------------Atributos-------------------------- } \\
\hline & $\mathrm{X}$ & $\mathrm{Y}$ & $\mathrm{Z}$ & Aparência & Aroma & Textura & Sabor & I. Global \\
\hline 1 & $20 \%$ & $85 \%$ & $5 \%$ & 5,7 & 6,3 & 6,9 & 6,5 & 6,3 \\
\hline 2 & $35 \%$ & $85 \%$ & $5 \%$ & 6,2 & 6,6 & 7,0 & 6,9 & 7,0 \\
\hline 3 & $20 \%$ & $115 \%$ & $5 \%$ & 5,8 & 6,5 & 7,3 & 6,9 & 6,7 \\
\hline 4 & $35 \%$ & $115 \%$ & $5 \%$ & 5,5 & 6,6 & 7,2 & 6,8 & 6,6 \\
\hline 5 & $20 \%$ & $85 \%$ & $7,5 \%$ & 5,9 & 6,4 & 6,3 & 6,2 & 6,3 \\
\hline 6 & $35 \%$ & $85 \%$ & $7,5 \%$ & 5,9 & 6,2 & 6,6 & 5,3 & 5,9 \\
\hline 7 & $20 \%$ & $115 \%$ & $7,5 \%$ & 5,9 & 6,8 & 6,0 & 6,0 & 6,3 \\
\hline 8 & $35 \%$ & $115 \%$ & $7,5 \%$ & 6,0 & 6,4 & 7,1 & 6,7 & 5,9 \\
\hline 9 & $14,9 \%$ & $100 \%$ & $6,25 \%$ & 5,4 & 6,3 & 6,4 & 5,9 & 6,0 \\
\hline 10 & $40,1 \%$ & $100 \%$ & $6,25 \%$ & 5,8 & 6,2 & 7,2 & 5,9 & 6,2 \\
\hline 11 & $27,5 \%$ & $74,8 \%$ & $6,25 \%$ & 5,9 & 6,5 & 6,9 & 5,6 & 6,1 \\
\hline 12 & $27,5 \%$ & $125,2 \%$ & $6,25 \%$ & 6,1 & 5,8 & 5,8 & 5,8 & 5,8 \\
\hline 13 & $27,5 \%$ & $100 \%$ & $4,15 \%$ & 6,3 & 6,4 & 6,4 & 6,4 & 6,2 \\
\hline 14 & $27,5 \%$ & $100 \%$ & $8,35 \%$ & 5,5 & 6,1 & 6,7 & 5,8 & 5,9 \\
\hline 15 & $27,5 \%$ & $100 \%$ & $6,25 \%$ & 5,3 & 6,3 & 6,8 & 6,4 & 6,3 \\
\hline 16 & $27,5 \%$ & $100 \%$ & $6,25 \%$ & 6,1 & 6,9 & 6,6 & 6,5 & 6,5 \\
\hline 17 & $27,5 \%$ & $100 \%$ & $6,25 \%$ & 5,7 & 6,2 & 6,7 & 5,7 & 6,1 \\
\hline 18 & $27,5 \%$ & $100 \%$ & $6,25 \%$ & 5,7 & 6,4 & 6,5 & 5,0 & 5,6 \\
\hline
\end{tabular}

*X - concentração de polvilho azedo; Y - concentração de açúcar, em relação à concentração $100 \%$ de açúcar da formulação padrão; Z concentração de farinha de albedo de laranja.

treinados, escolhidos ao acaso, de diferentes faixas etárias e sexo, pertencentes ao corpo de estudantes e funcionários da Universidade Federal de Sergipe, os quais preencheram em uma ficha a impressão que o biscoito, como um todo, causou-lhes, para as características aparência, aroma, textura e sabor, além da impressão global. As amostras foram apresentadas de forma monádica, utilizando-se a escala hedônica estruturada de nove pontos $(9=$ gostei muitíssimo, 5 = não gostei, nem desgostei, $1=$ desgostei muitíssimo). No teste de intenção de compra, foi utilizada a escala hedônica estruturada de sete pontos ( 7 = certamente compraria, $4=$ talvez comprasse/talvez não comprasse, 1 = certamente não compraria).

Os parâmetros de otimização foram definidos por meio do planejamento fatorial, com os cálculos de ANOVA, e os coeficientes de determinação obtidos a partir do programa Statistic/Windows, versão 8.0. Os resultados das análises físico-químicas e dos testes afetivos foram avaliados estatisticamente, para obtenção de média e desvio padrão, e submetidos à análise de variância $(\mathrm{P}<0,05)$ e ao teste de Tukey, para comparação entre as médias utilizando o programa ASSISTAT, versão 7.5 beta.

\section{RESULTADOS E DISCUSSÃO}

A farinha de albedo de laranja apresentou

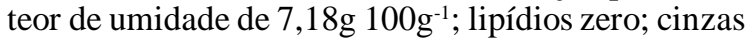

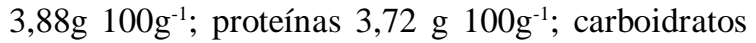

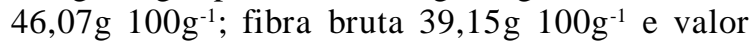
energético $199,16 \mathrm{kcal}^{100 \mathrm{~g}^{-1}}$. Os teores de umidade, lipídios e valor energético da farinha de albedo de laranja estão de acordo com LARRAURI (1999), que

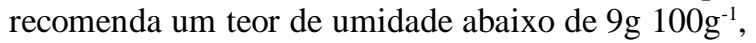
baixos teores de lipídios e baixo valor energético, menor que $199,81 \mathrm{kcal}^{1} 100 \mathrm{~g}^{-1}$ para o pó de fibra dietética obtido de subprodutos de frutas.

Na tabela 1, encontram-se as médias obtidas no teste sensorial dos biscoitos. As médias situaramse entre 5,0 e 7,3, correspondentes aos termos hedônicos "não gostei, nem desgostei" e "gostei moderadamente", para todos os atributos sensoriais avaliados.

A tabela 2 apresenta os valores de $\mathrm{p}$ para as características sensoriais do teste de ANOVA para os biscoitos preparados com farinhas mistas de polvilho azedo e farinha de albedo de laranja. Não houve constituinte influenciando significativamente $(\mathrm{P} \leq 0,05)$ as respostas dos provadores para as características sensoriais de aparência, aroma, textura, sabor e impressão global. Assim, as variações das médias da preferência das características sensoriais não puderam ser explicadas por nenhuma das variações de concentração de polvilho azedo, açúcar e farinha de albedo de laranja aplicadas no planejamento experimental. Desse modo, pôde-se escolher a 
Tabela 2 - Valores de $p$ para as características sensoriais dos biscoitos com incorporação de diferentes teores de polvilho azedo, açúcar e farinha de albedo de laranja.

\begin{tabular}{|c|c|c|c|c|c|}
\hline \multirow{2}{*}{ Constituintes } & \multicolumn{5}{|c|}{ } \\
\hline & Aparência & Aroma & Textura & Sabor & Impressão global \\
\hline Polvilho azedo (1) & 0,4642 & 0,7573 & 0,1039 & 0,9794 & 0,5491 \\
\hline Polvilho azedo quadrático & 0,6177 & 0,8225 & 0,4049 & 0,5464 & 0,4431 \\
\hline Açúcar (2) & 0,2658 & 0,9267 & 0,4272 & 0,4038 & 0,9092 \\
\hline Açúcar quadrático & 0,6950 & 0,9285 & 0,6596 & 0,8750 & 0,8185 \\
\hline Albedo de laranja(3) & 0,5316 & 0,6620 & 0,2450 & 0,1102 & 0,2701 \\
\hline Albedo de laranja quadrático & 0,7947 & 0,6239 & 0,8270 & 0,3129 & 0,5863 \\
\hline 1 e 2 & 0,5188 & 0,7063 & 0,6300 & 0,5404 & 1,0000 \\
\hline 1 e 3 & 0,8702 & 0,2750 & 0,2518 & 0,8080 & 0,7205 \\
\hline 2 e 3 & 0,5188 & 0,5333 & 0,7962 & 0,5985 & 0,5194 \\
\hline $\mathrm{R}^{2}$ & 0,33 & 0,24 & 0,52 & 0,43 & 0,29 \\
\hline
\end{tabular}

formulação otimizada que foi de $35 \%$ de polvilho azedo, $100 \%$ de açúcar e 7,5\% de farinha de albedo de laranja.

A concentração de $35 \%$ de polvilho azedo foi escolhida com o propósito de agregar maior valor econômico aos produtos derivados da mandioca. Também baseou-se no resultado apresentado por KIM (1972) citado por TSEN (1976), na proporção de 25\% de substituição, que não verificou modificações nas características de qualidade nos biscoitos com farinhas mistas de fécula de mandioca e trigo.

A concentração de $100 \%$ de açúcar foi escolhida com o propósito de fornecer um biscoito com teor mais baixo de açúcar, sendo nutricionalmente aceitável, considerando que tal componente contribui para maior índice de obesidade, diabetes e cárie dentária (MARCELLINI et al., 2006). Entretanto, o açúcar é um componente essencial, pois confere efeitos positivos à textura, ao sabor (doçura), volume e à cor dos biscoitos (MORETTO \& FETT, 1999).

A concentração de $7,5 \%$ de farinha de albedo de laranja foi escolhida, respeitando a classificação proposta pela legislação brasileira que estabelece que, para um alimento sólido ser considerado "fonte de fibras", estas devem estar presentes em, no mínimo, $3 \mathrm{~g}$ para cada $100 \mathrm{~g}$ do alimento, e para ser classificado como "alto teor" deve apresentar o mínimo de $6 \mathrm{~g}$ por $100 \mathrm{~g}$ do alimento (BRASIL, 1998).

Na tabela 3, encontram-se os resultados do teste sensorial dos biscoitos comercial, padrão e otimizado. Os resultados indicam que os biscoitos apresentaram as médias sensoriais entre 5,6 e 7,2. A ANOVA revelou diferença significativa $(\mathrm{P} \leq 0,05)$ para as características sensoriais aparência, textura e sabor dos biscoitos. O biscoito comercial foi o preferido quanto à aparência, e o biscoito padrão quanto ao sabor e textura. Quanto à intenção de compra, as médias situaram-se na região referente ao termo hedônico "talvez comprasse, talvez não comprasse" (nota 4). O biscoito padrão apresentou a maior média de aceitação $(4,9)$, embora não tenha diferido significativamente $(\mathrm{P} \leq 0,05)$ do biscoito otimizado.

Os resultados das análises físico-químicas dos biscoitos comercial, padrão e otimizado estão apresentados na tabela 4 . Os teores de umidade dos biscoitos (Tabela 4) apresentaram diferença

Tabela 3 - Valores médios da avaliação sensorial e do teste de intenção de compras para os biscoitos: comercial, padrão e otimizado.

\begin{tabular}{|c|c|c|c|c|c|c|}
\hline \multirow{2}{*}{ Biscoitos } & \multicolumn{5}{|c|}{ 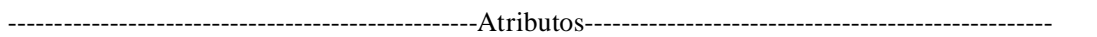 } & \multirow{2}{*}{$\begin{array}{l}\text { Intenção de } \\
\text { compra }\end{array}$} \\
\hline & Aparência & Aroma & Textura & Sabor & Impressão global & \\
\hline Comercial & $7,2^{\mathrm{a} 2}$ & $6,4^{\mathrm{a}}$ & $7,0^{\mathrm{a}}$ & $5,7^{\mathrm{b}}$ & $6,4^{\mathrm{a}}$ & $4,2^{\mathrm{b}}$ \\
\hline Padrão & $5,8^{\mathrm{b}}$ & $6,1^{\mathrm{a}}$ & $6,2^{\mathrm{b}}$ & $7,2^{\mathrm{a}}$ & $6,7^{\mathrm{a}}$ & $4,9^{\mathrm{a}}$ \\
\hline Otimizado & $5,6^{\mathrm{b}}$ & $5,9^{\mathrm{a}}$ & $7,0^{\mathrm{a}}$ & $6,3^{\mathrm{b}}$ & $6,3^{\mathrm{a}}$ & $4,5^{\mathrm{ab}}$ \\
\hline $\mathrm{DMS}^{1}$ & 0,53 & 0,50 & 0,54 & 0,61 & 0,48 & 0,58 \\
\hline
\end{tabular}

${ }^{1}$ Diferença mínima significativa;

${ }^{2}$ Médias com letras iguais, na mesma coluna, indicam não haver diferença significativa entre si pelo teste de Tukey a 5\% de probabilidade.

Ciência Rural, v.41, n.3, mar, 2011. 
Tabela 4 - Composição físico-química do biscoito comercial, padrão e otimizado.

\begin{tabular}{|c|c|c|c|}
\hline Característica & Comercial & Padrão & Otimizado \\
\hline Umidade $\left(\mathrm{g} 100 \mathrm{~g}^{-1}\right)$ & $3,06^{\mathrm{a} 2} \pm 0,22^{3}$ & $2,10^{\mathrm{b}} \pm 0,12$ & $1,52^{\mathrm{c}} \pm 0,02$ \\
\hline Lipídios $\left(\mathrm{g} 100 \mathrm{~g}^{-1}\right)$ & $8,12^{\mathrm{b}} \pm 0,12$ & $14,39^{\mathrm{a}} \pm 0,18$ & $14,32^{\mathrm{a}} \pm 0,47$ \\
\hline Cinzas $\left({\left.\mathrm{g} 100 \mathrm{~g}^{-1}\right)}\right.$ & $2,27^{\mathrm{a}} \pm 0,03$ & $1,42^{\mathrm{b}} \pm 0,17$ & $1,47^{\mathrm{b}} \pm 0,10$ \\
\hline Proteínas $\left(\mathrm{g} 100 \mathrm{~g}^{-1}\right)$ & $9,88^{\mathrm{a}} \pm 0,19$ & $6,84^{\mathrm{b}} \pm 0,09$ & $4,48^{\mathrm{c}} \pm 0,18$ \\
\hline 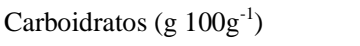 & 76,68 & 74,69 & 75,13 \\
\hline Fibra Bruta $\left({\left.\mathrm{g} 100 \mathrm{~g}^{-1}\right)}^{1}\right.$ & - & $0,56 \pm 0,05$ & $3,08 \pm 0,26$ \\
\hline Fibra Alimentar ${ }^{1}\left({\left.\mathrm{~g} 100 \mathrm{~g}^{-1}\right)}\right.$ & 2,00 & - & - \\
\hline Valor Energético $\left(\right.$ Kcal $\left.100 \mathrm{~g}^{-1}\right)$ & 419,32 & 455,63 & 447,32 \\
\hline
\end{tabular}

${ }^{1}$ Valor declarado no rótulo do biscoito;

${ }^{2}$ Letras iguais na mesma linha indicam não haver diferença significativa entre si pelo teste de Tukey a 5\% de probabilidade;

${ }^{3}$ Desvio padrão.

significativa $(\mathrm{P}<0,05)$ entre si. No entanto, estes valores se situam abaixo de $14,0 \%$ de umidade (BRASIL, 1978). Quanto ao teor de lipídios, o biscoito comercial diferiu estatisticamente dos demais biscoitos.

O teor de cinzas do biscoito comercial apresentou-se maior e diferiu significativamente dos demais biscoitos, enquanto os biscoitos padrão e otimizado, não diferiram entre si. Para os teores de proteínas, os biscoitos diferiram consideravelmente entre si, sendo que o comercial apresentou o maior teor.

Com relação ao teor de fibra bruta, o biscoito

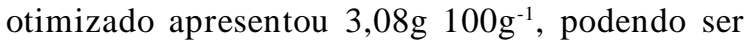
classificado como alimento "fonte de fibras", já que este valor enquadra-se no mínimo necessário de $3 \mathrm{~g}$ $100 \mathrm{~g}^{-1}$ para um alimento sólido, conforme descrito na Portaria 27/98 da ANVISA (BRASIL, 1998).

O biscoito padrão obteve o valor calórico de 455,63 Kcal $100 \mathrm{~g}^{-1}$, já o valor energético do biscoito otimizado (447,32 Kcal $\left.100 \mathrm{~g}^{-1}\right)$ foi reduzido com a adição de farinha de albedo de laranja, agregando, assim, valor nutricional aos biscoitos. O biscoito comercial apresentou o menor valor energético $(419,32 \mathrm{Kcal}$ $\left.100 \mathrm{~g}^{-1}\right)$, dentre os biscoitos analisados.

\section{CONCLUSÃO}

A formulação otimizada para os biscoitos preparados com farinhas mistas de polvilho azedo e farinha de albedo de laranja apresentou $35 \%$ de polvilho azedo, $100 \%$ de açúcar, 7,5\% de farinha de albedo de laranja e $7 \%$ de achocolatado.

No teste de aceitação os biscoitos padrão e otimizado apresentaram significativa preferência $(\mathrm{P}<0,05)$ na análise de intenção de compra em relação ao biscoito comercial.

A adição de um produto (polvilho azedo) $\mathrm{e}$ um subproduto (albedo de laranja), nos níveis utilizados para a formulação de biscoitos no presente estudo, permitiu a elaboração de um alimento com elevado teor de fibras, sem comprometimento dos atributos sensoriais.

\section{REFERÊNCIAS}

ASSOCIATION OF OFFICIAL ANALYTICAL CHEMISTS. Official Methods of Analysis of AOAC International. CD-ROM. $17^{\text {th }}$ edition, Arlington, VA: AOAC International, 2000 .

ASSISTAT - Assistência Estatística. Versão 7.5 beta (2008). Disponível em: <http://www.assistat.com/indexp.html>. Acesso em: 24 outubro 2009.

BRASIL, Comissão Nacional de Normas e Padrões para Alimentos - CNNPA. Resolução - CNNPA no 12 , de 1978 de 24 de julho de 1978. Aprova as normas técnicas especiais. Diário Oficial da República Federativa do Brasil, Brasília, 24 jul. 1978. Disponível em: <http://www.anvisa.gov.br/legis/resol/ 12_78.pdf>. Acesso em: 04 dezembro 2009.

BRASIL. Ministério da Saúde, Agência Nacional de Vigilância Sanitária. Portaria ${ }^{\circ} 27$, de 13 de janeiro de 1998. Regulamento técnico referente à informação nutricional complementar (declarações relacionadas ao conteúdo de nutrientes). Diário Oficial da União, de 16 de janeiro de 1998. Disponível em: <http://e-legis.bvs.br/leisref/public/showAct.php>. Acesso em: 04 dezembro 2009.

BRASIL. Ministério da Saúde, Agência Nacional de Vigilância Sanitária. Resolução - RDC no 263 de 22 de setembro de 2005. Aprova o regulamento técnico para produtos de cereais, amidos, farinhas e farelos. Diário Oficial da União, Brasília, 22 set. 2005. Disponível em: <http://e-legis.anvisa.gov.br/leisref/public/ showAct.php?id=18822\&word=> Acesso em 03 dezembro 2009.

DEMIATE, I. M.; CEREDA, M. P. Some physico-chemical characteristics of modified cassava starches presenting baking property. Energia na Agricultura, v. 15, n. 3, p. 36-46, 2000 .

EL-DASH, A. et al. Tecnologia de farinhas mistas. Brasília: EMBRAPA. 1994a. v. 1 (Uso de farinha mista de trigo e mandioca na produção de pães). 88 p. 
EL-DASH, A. et al. Tecnologia de farinhas mistas. Brasília: EMBRAPA. 1994b. v. 6 (Uso de farinha mista na produção de biscoitos). $47 \mathrm{p}$.

EMBRAPA. Mandioca. Disponível em: <http://www.cnpmf.embrapa.br/ index.php?p=pesquisa-culturas_pesquisadas-mandioca.php>. Acesso em: 07 março 2010.

FASOLIN, L. H. et al. Biscoitos produzidos com farinha de banana: avaliações química, física e sensorial. Ciência e Tecnologia de Alimentos, v. 27, n. 3, p. 524-529, jul.-set. 2007. Disponível em: <http://www.scielo.br/scielo.php?script=sci_arttext\&pid=S010120612007000300016\&lng=pt\&nrm=iso>. Acesso em: $20 \mathrm{dez}$. 2010. doi: 10.1590/S0101-20612007000300016.

GONÇALVES, L. C.et al. Reciclagem das cascas da laranja pêra na produção de suplemento alimentar de fibras solúveis (pectina). IN: $21^{\circ}$ CONGRESSO BRASILEIRO DE ENGENHARIA SANITÁRIA E AMBIEnTAL, 2001, João Pessoa. Anais... Rio de Janeiro: ABES, 2001. Disponível em: <http://www.bvsde.paho.org/bvsaidis/ resisoli/brasil/iii-131.pdf>. Acesso em: 08 março 2010.

GUTKOSKI, L. C. et al. Avaliação de farinhas de trigos cultivados no Rio Grande do Sul na produção de biscoitos. Ciência e Tecnologia de Alimentos, v. 23 (Supl). p. 91-97, dez. 2003. Disponível em: <http://www.scielo.br/scielo.php?script=sci_arttext\&pid=S010120612003000400017\&lng=pt\&nrm=iso>. Acesso em: 20 dez. 2010. doi: 10.1590/S0101-20612003000400017.

INSTITUTO ADOLFO LUTZ. Normas Analíticas do Inst. Adolfo Lutz. $4^{\text {a }}$ Ed. São Paulo: Instituto Adolfo Lutz, 2005. $1018 \mathrm{f}$.

ÍTAVO, L. C. V. et al. Composição e Digestibilidade Aparente da Silagem de Bagaço de Laranja. Revista Brasileira de Zootecnia, v. 29, n. 5, p. 1485-1490, 2000. Disponível em: <http:// www.scielo.br/scielo.php?script $=$ sci_arttext $\&$ pid $=S 1516$ $35982000000500029 \& \operatorname{lng}=$ pt\&nrm=iso>. Acesso em: $20 \mathrm{dez}$. 2010. doi: 10.1590/S1516-35982000000500029.

KIM, J. C. Manufacturing biscuits from composite flours. Bogota, Colombia. Composite Flour Sym. Technological Institute, 1972. 89p.

LARRAURI, J. A. New approaches in the preparation of high dietary fibre powders from fruit by-products. Food Science and Technology, v. 10, p. 3-8, 1999. Disponível em: <http:// www.sciencedirect.com/science?_ob=ArticleURL\&_udi=B6VHY$3 \mathrm{WK} 3 \mathrm{~S} 2 \mathrm{~N}-2 \&$ _user $=10 \&$ \&coverDate $=01 \% 2 \mathrm{~F} 31 \%>$. Acesso em: 18 dez. 2010. doi: 10.1016/S0924-2244(99)00016-3.

MARCELLINI, P. S. et al. Caracterização sensorial de suco de abacaxi concentrado, reconstituído e adoçado com diferentes edulcorantes e sacarose. Alimentos e Nutrição, v. 17, n. 2, p. 143-150, abr./jun. 2006. Disponível em: <http://200.145.71.150/ seer/index.php/alimentos/article/view/254/249>. Acesso em: 20 dez. 2010.

MORETTO, E.; FETT, R. Processamento e análise de biscoitos. São Paulo: Varela, 1999. 97p.

SANTANA, M. de. F. S. de. Caracterização físico-química de fibra alimentar de laranja e maracujá. 2005. 188p. Tese (Doutorado em Engenharia de Alimentos). Faculdade de Engenharia de Alimentos, Departamento de Engenharia de Alimentos, Universidade Estadual de Campinas.

STATISTICA for Windows - Release 8.0 A. Tulsa, OK, USA: Stat Soft, Inc., 2006. Cd-rom.

TSEN, C. C. Regular and protein fortified cookies from composite flours. Cereal Foods Word, v. 21, n. 12, p. 633 640, 1976. 